\title{
Mothers' and fathers' sense of security in the context of pregnancy, childbirth and the postnatal period: an integrative literature review
}

Therese Werner-Bierwisch ${ }^{1,2,3^{*}}$ (D), Christiane Pinkert ${ }^{2,3}$, Karin Niessen ${ }^{2,3}$, Sabine Metzing ${ }^{1,2}$ and Claudia Hellmers 2,3

\begin{abstract}
Background: From the individual perspective, security, which is essential to life quality, is characterised as an elementary human need that requires fulfilment. During the transition to parenthood, mothers and fathers are confronted with changes in physical and psychosocial processes that are accompanied by uncertainty and insecurity. Feelings of insecurity may have consequences affecting their pregnancy and childbirth experiences as well as their adaption to the parental role in the first weeks following childbirth. In this context, it is important to understand how parents express and interpret their sense of security to effectively support their security needs. This integrative review aimed to provide a critical synthesis of existing research on parents' experiences of their sense of security associated with pregnancy, childbirth and the postnatal period.

Methods: A literature search of the PubMed, CINAHL, PsycINFO and GESIS Sowiport databases was performed. Peer-reviewed papers that were published in English or German between 1990 and 2017 focusing on mothers' and fathers' experiences of sense of security in the context of maternity care were included. A thematic analysis was performed to organise and describe the findings.

Results: Eleven research-based papers met the inclusion criteria. Four key themes among the data were analysed: the meaning and manifestation of sense of security, sense of security in relation to confidence and control, lack of feeling secure and coping strategies, and factors influencing sense of security.

Conclusions: The findings revealed a complex profile of the perception of security associated with pregnancy, childbirth and the postnatal period. Sense of security can depend on multiple internal and external factors, which can differ between mothers and fathers. Research on the experiences and perceptions associated with fathers' sense of security is lacking. Further research focused on the experiences of security from the parents' perspective is necessary. Midwives and other involved health professionals should be aware of their role in creating a sense of security among parents. Based on a local specific understanding of security experiences, professional caregivers have the opportunity to support parents more effectively with regard to their specific security needs.
\end{abstract}

Keywords: Sense of security, Mothers, Fathers, Pregnancy, Childbirth, Postnatal period, Literature review

* Correspondence: Therese.Werner-Bierwisch@uni-wh.de

${ }^{1}$ Faculty of Health, Department of Nursing Science, Witten/Herdecke

University, Stockumer Strasse 12, 58453 Witten, Germany

${ }^{2}$ Research Group 'FamiLe - Family Health in Life Course', Witten and

Osnabrück, Germany

Full list of author information is available at the end of the article

(c) The Author(s). 2018 Open Access This article is distributed under the terms of the Creative Commons Attribution 4.0 International License (http://creativecommons.org/licenses/by/4.0/), which permits unrestricted use, distribution, and reproduction in any medium, provided you give appropriate credit to the original author(s) and the source, provide a link to the Creative Commons license, and indicate if changes were made. The Creative Commons Public Domain Dedication waiver (http://creativecommons.org/publicdomain/zero/1.0/) applies to the data made available in this article, unless otherwise stated. 


\section{Background}

Security is an essential part of the quality of life [1]. As a need required by all humans since the beginning of mankind, security affects nearly all aspects of human life and is therefore considered an "anthropological constant" [2]. In the transition to parenthood, expectant parents are exposed to personal, familial, and social changes [3, 4], which have important implications for the couple's relationship, the infant-parent relationship and the infant's development $[4,5]$. The reorganisation and preparation of new living conditions and new social roles may be accompanied by subjective uncertainties, insecurities and anxieties $[4,5]$. During pregnancy, a woman's physical changes can be perceived as very positive and contribute to great pride in the abilities of one's own body. On the other hand, these changes can be perceived as threatening because of the uncontrollable process, which can lead to a sense of insecurity and increase childbirth-related fear [6]. For expectant fathers, pregnancy can be accompanied by great joy, and thus a high degree of paternal involvement in pregnancy processes $[7,8]$, or by uncertainties and anxieties regarding the paternal role during pregnancy and childbirth [9-12]. Perceived insecurities associated with pregnancy and childbirth may have serious consequences regarding the childbirth experiences of mothers and fathers, their adaption to the parental role, and their attachment to the child during the postnatal period.

Security is a familiar term to most people; however, the term security has multiple meanings, and the intended meaning is not always clear [2, 13-15]. The definition of security is imprecisely differentiated from similar terms, such as safety $[16,17]$, certainty and dependability $[2,18-20]$, making finding a common basis for discussion difficult. A feature shared by most definitions is the distinction between objective and subjective dimensions of security. Objective security is described as an absence of threats $[15,17,19,21]$ and is accompanied by risk assessments, as lower risks are associated with a higher objective security $[22,23]$. However, objective security does not exist separate from the individual's perception [24], and the subjective perception of security can thus deviate from the objective state of security [15, $19,21,24]$. Therefore, this review begins with a theoretical discussion on the sense of security concept.

\section{The sense of security concept}

From the perspective of the individual, security is characterised as an elementary human need that requires fulfilment [19, 25-27]. Individuals strive for security to maintain the ability to act and to minimise the risk of being paralysed and unable to act [19]. In this process, decisions are made with the aim of producing the desired future results and thus reducing future insecurities $[2,27,28]$.
Sense of security is characterised by cognitive and affective components [24, 29]. On the one hand, sense of security is understood as a perception and thus represents a cognitive construction of the individual $[10,14$, 17], which includes the perception of a physical state with the sense of being protected against threats $[2,19$, $20,24,30]$. On the other hand, sense of security is commonly expressed as an individual emotion in which a person feels safe [16, 17], free from anxiety [15, 19, 21], carefree $[2,19,29]$, confident $[19,20,30]$ and without doubt $[2,19]$.

Feeling secure or insecure depends on diverse internal and external factors. The factors defining sense of security are an individual's perception of being vulnerable and at risk in addition to an assessment of one's own coping ability $[2,28,30]$. Gender, age, past experiences, personality traits, and information may also play roles in the creation of security [28, 31, 32]. Social science studies demonstrate a partial mismatch between the objective security of a given situation and the sense of security $[20,28,30,31,33]$. An individual can feel secure despite the presence of objective danger because the danger is not recognised or perceived as such [19]. On the other hand, a person may feel secure despite an objective danger due to perceived coping abilities $[19,28,30]$ or self-confidence $[19,20]$. However, the subjective perception of security is strongly dependent on the context; therefore, the specific factors are relative and not equally relevant in all spheres of life [32].

Analysis of the social science literature shows that no clear dividing line exists between feeling safe and feeling secure; both terms are often used synonymously, indicating that the concepts of security and safety are interwoven [16]. Bar-Tal and Jacobson [24] argue that maintaining physical safety is a prerequisite for a subjective perception of security, which they consider to be a psychological need.

In the context of maternity care, the feeling of security is described as one of the elementary aspects of a mother's overall birth experience [34-38] and, for example, plays an important role in the maintenance of breastfeeding during the postnatal period [39]. According to Mozygemba [6], women strive for security during pregnancy and birth to orientate themselves during the processes of change. Further studies focusing on childbirth experiences indicate that the presence and professional support offered by midwives and hospital staff contribute to creating a sense of security for mothers [40-44] and fathers [43, 45-48]. Additionally, the partner's presence at the delivery is considered beneficial for the women's sense of security [49-51]. Moreover, absence of the midwife from the delivery room or not knowing how to support the woman can create a sense of insecurity for the father $[43,52]$. 
Ideas regarding what contributes to the feeling of security can differ between the supporting midwives and the parents; while women and their partners consider the midwife's presence important to their sense of security, the midwives do not explicitly describe their own presence as supporting the parents' sense of security during labour [43].

\section{Safety and risk concepts in the obstetric context}

In most Western societies, the contemporary childbirth culture is embedded in concepts of safety and risk. In this context, the concept of safety represents a quality feature of maternity care, as it aims to reduce the risk of unnecessary harm for mothers and their babies to an acceptable minimum [53]. The declaration of the concept of risk as "the key to safety" [54] results in understanding pregnancy, childbirth and the postnatal period as potential risks [55, 56], which fosters the medicalisation of pregnancy and childbirth [57-59]. It appears that the concepts of safety and risk complement one another and have a restrictive effect on giving birth. In this context, parents are confronted with rules and normative views of a maternity healthcare system that influence their attitudes, decisions and actions.

Studies regarding the perception of safety in the context of maternity care indicate that the safety concept is differentially perceived and interpreted. For some women, safety is associated with medical-technical care and thus also with risk minimisation [60-63]. For other women, being safe means avoiding routine interventions, giving birth in a calm and private atmosphere, having confidence in the ability to give birth or having trust in God [61, 62]. The various interpretations of safety are associated with different attitudes towards childbirth and the competence of the female body to perform birth. On the one hand, pregnancy and childbirth are understood as fundamental medical processes that require medical skills and technology $[60,61,63,64]$; on the other hand, they are perceived as natural processes that do not require medical interventions or professional assistance [61-63]. In addition, the perception of safety can be influenced both negatively and positively by the care offered by midwives and other professionals [65-67]. The birth experience itself, including the experience of pain and the birth of a healthy child, can also retrospectively influence a woman's view of safety [68]. Further studies demonstrate that the various perceptions of safety have a decisive impact on women's choice of where to give birth, such that both the hospital and the home are considered safe birthplaces for women [60-63, 66, 69, 70].

Research has revealed different meanings of safety and different needs of women. The results underline that women's perception of safety goes beyond the medical understanding and is influenced by other cultural, emotional and psychosocial aspects.
We acknowledge the existence of a possible overlap between the concepts of safety and security. Furthermore, the concepts of safety and risk in maternity care presumably influence the sense of security.

\section{Formulation of the problem}

Theoretical and empirical literature characterise subjective perceived security as an elementary human need that requires fulfilment. During the transition to parenthood, mothers and fathers are confronted with physical and psychosocial changes that are accompanied by uncertainty and insecurity. Feelings of insecurity may have consequences for parents' pregnancy and childbirth experiences, adaption to the parental role, and attachment to the child.

However, no study to date has critically synthesised the research literature regarding sense of security from the perspective of parents in the context of maternity care. This paper presents an integrative review of the literature addressing parents' sense of security associated with pregnancy, childbirth and the postnatal period. For the purposes of this paper, sense of security has been defined as an emotional state in which an individual feels safe, confident and free from doubt and anxiety. A critical synthesis of current knowledge regarding parents' security experiences in the context of maternity care is important for understanding and effectively supporting mothers and fathers with regard to their specific security needs.

\section{Methods}

Aim

This review aimed to provide a critical synthesis of research concerning parents' experiences of sense of security in association with pregnancy, childbirth and the postnatal period. The following research questions guided this review:

1. How do parents experience a sense of security in the context of pregnancy, childbirth and the postnatal period, and how does it manifest?

2. Which factors influence parents' sense of security?

\section{Methodology}

The integrative literature review method is considered the most appropriate method for exploring the status of available literature with diverse methodologies [71]. This literature review is based on Whittemore and Knafl's [71] five-step recommendation: formulation of the problem, literature search, evaluation of data, data analysis, and presentation of the results.

\section{Literature search}

A three-step screening process was used to identify relevant publications. Step one involved a broad search of the electronic databases PubMed, CINAHL, PsycINFO and GESIS Sowiport. Studies published in English or 
German between January 1990 and April 2017 were explored. The decision to start the literature search in 1990 was based on the assumption that medical-technical care and increasing intervention rates beginning in the 1990s may have impacted the sense of security concept. In addition to the database search, a manual search of the reference lists of relevant publications was performed. Both German and English search terms were used, and the keywords security, sense of security, feeling safe, experience, perception, pregnancy, labour and delivery, childbirth, postnatal period, postpartum period and postpartum care, were used in various combinations with medical subject headings (MeSH) and free text words.

The literature search (Fig. 1) identified 3606 potential articles from the databases and an additional 36 studies from the reference lists. In the second step, after the exclusion of duplicates, 3186 titles and abstracts were screened for relevance according to the research questions. Third, of the remaining 99 full-text articles, manuscripts were included only if they focused on mothers', fathers' or parents' experiences of sense of security during pregnancy, childbirth and the postnatal period.

To obtain a comprehensive profile of sense of security, studies were also included if the phenomenon was described as one of several results in the context of pregnancy and childbirth experiences. Studies in which the views of mothers/fathers were combined with those of professionals in the results analysis as well as studies focusing on views from the perspectives of nurses, midwives and obstetricians were excluded. A total of 11 research reports met the inclusion criteria, including nine qualitative studies and two studies that utilised a quantitative approach. The first author searched databases and manually searched reference lists, screened relevant titles and abstracts, and identified potential papers for inclusion. The inclusion of potential papers was discussed with two other authors.

\section{Evaluation of data}

The scientific rigour of the included studies was appraised using checklists provided by Critical Appraisal Skills Programme (CASP) tools. The validity and quality of the qualitative studies were assessed using the CASP Qualitative Checklist [72]. Analogous to the CASP Qualitative Checklist, the included quantitative studies with a cross-sectional design were assessed with the same critical appraisal method using the CASP Cohort Study Checklist [73]. While the evaluation criteria of the CASP Cohort Study Checklist are highly similar to those

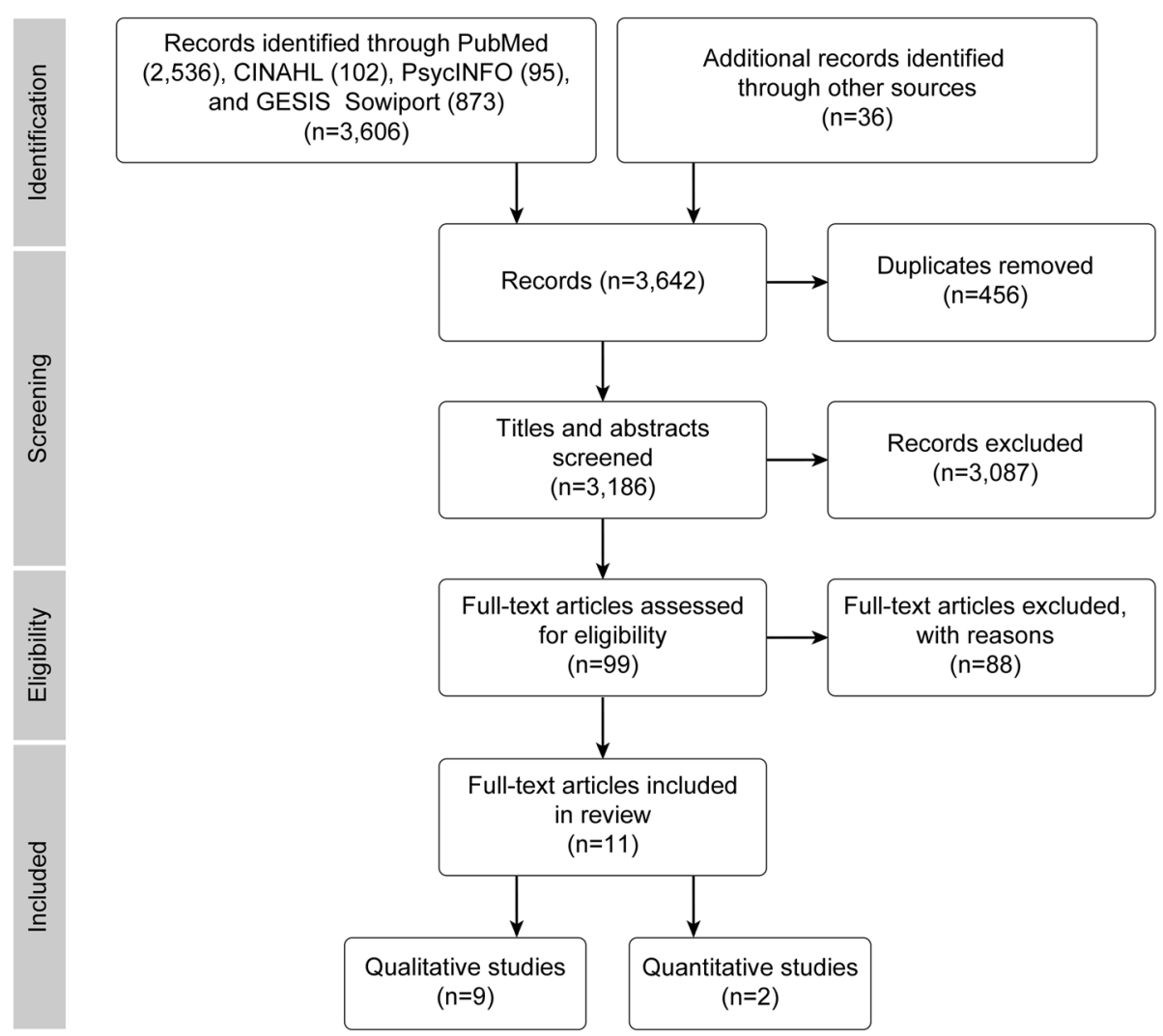

Fig. 1 PRISMA flow diagram of the search strategy outcomes 
of cross-sectional checklists [74], the scope is smaller and more manageable. Critical appraisal of all included studies was performed by the first author. Of these studies, five were appraised independently by a second researcher to ensure consistency in the appraisals between researchers. Some of the included studies did not meet all the qualitative criteria but provided important insights into the sense of security phenomenon. Therefore, no studies were excluded after the appraisal process. The appraisal details of the critical evaluation are presented in Table 1.

\section{Data analysis}

The 11 remaining studies were synthesised under the following subheadings and recorded on a data-coding sheet: author and country, objective, study sample and inclusion criteria, research design, data collection method(s), instrument(s), method of analysis, key findings regarding experiences of sense of security and limitations (Table 2).

There is no gold standard for the analysis of data in an integrative review [71]. The method used for the interpretation of data in this review was a thematic analysis, which is a flexible method for identifying, analysing and reporting prominent themes within data [75] and a means of integrating qualitative and quantitative evidence. To accomplish the aim of this review, themes were initially identified from the results of each study, and patterns, similarities and differences among the included articles were then defined. In the second step, factors that influence sense of security were coded in a deductive manner to answer the research question. The identified themes were then discussed among authors.

\section{Results}

The studies selected for this review used qualitative $(n=9)$ and quantitative $(n=2)$ methodologies. The majority of the included studies were based on interviews with pregnant women or mothers [76-82]. In two studies, the mothers were interviewed together with their partners $[83,84]$. Only two relevant studies focusing on the perspective of the fathers were identified $[85,86]$.

Sense of security received different degrees of attention in the included studies and was expressed in both similar and different terms. In some studies, security and safety were used synonymously without an exact description [76]. Further studies used the terms feeling safe, feeling secure, feeling safe and secure [77, 78, 85], sense of safety [83], or personal security [81]. Most studies used the term sense of security [79, 80, 82-84, 86], where this concept was described by the authors and coincided with the essential points of the definition used in this review [79-82, 86].

Four key themes identified from the data were analysed: the meaning and manifestation of sense of security, sense of security in relation to confidence and control, lack of feeling secure and coping strategies and factors influencing sense of security.

\section{Theme 1. The meaning and manifestation of sense of security}

The feeling of security was characterised as a mother's essential need while giving birth [77] and as a central issue for women during pregnancy and childbirth or for parents in the first week after birth [76, 83]. Karlström et al. [78] reported that feeling safe and secure was an essential part of women's positive birth experience. Perceptions of what feels safe influenced the mothers' behaviours and decisions at any time during pregnancy, birth and the first postnatal weeks [76, 79, 83, 84].

Melender and Lauri $[79,80]$ investigated how the feeling of security manifests in women. Security is revealed in one's own resources and in feelings of comfort, calmness, joy, positive self-awareness, satisfaction and confidence that everything will go well. Everyday life (without focusing exclusively on pregnancy) has been described as a manifestation of security. With regard to pregnancy, an orientation towards the child and home preparation for birth are perceived as expressions of security by women [79]. Halldorsdottir and Karlsdottir [77] reported that during the childbirth journey, security manifested in a 'go with the flow' attitude towards the body and as a companion to the birth pains upon fulfilment of the need for security by a caring midwife and a present partner.

Regarding the experience of fathers, sense of security is described as an important factor influencing their decisions and behaviour during the postnatal period [83]. The importance of feeling secure is expressed in the desire of fathers' participation during pregnancy, childbirth and the early postnatal period and in the need to be prepared for the baby, birth and fatherhood [83-86]. Fathers' participation in care has a positive effect on mothers' postnatal sense of security [84].

\section{Theme 2. Sense of security in relation to confidence and control}

Relevant studies have indicated an association between sense of security and feelings of control and confidence [77-79, 81, 83]. Women who have confidence in themselves, their body and their ability to give birth feel secure during pregnancy or in the childbearing process and describe their birth experiences very positively [78]. The promotion of security during care leads to a reduction in anxiety and is conducive to a sense of control during the birth experience $[78,79]$. Namey and Lyerly [81] describe personal security as part of the control concept, as it allows women to cope with the birth situation while minimising anxiety. Persson et al. [82] draw the same conclusion, revealing that reduced anxiety, 


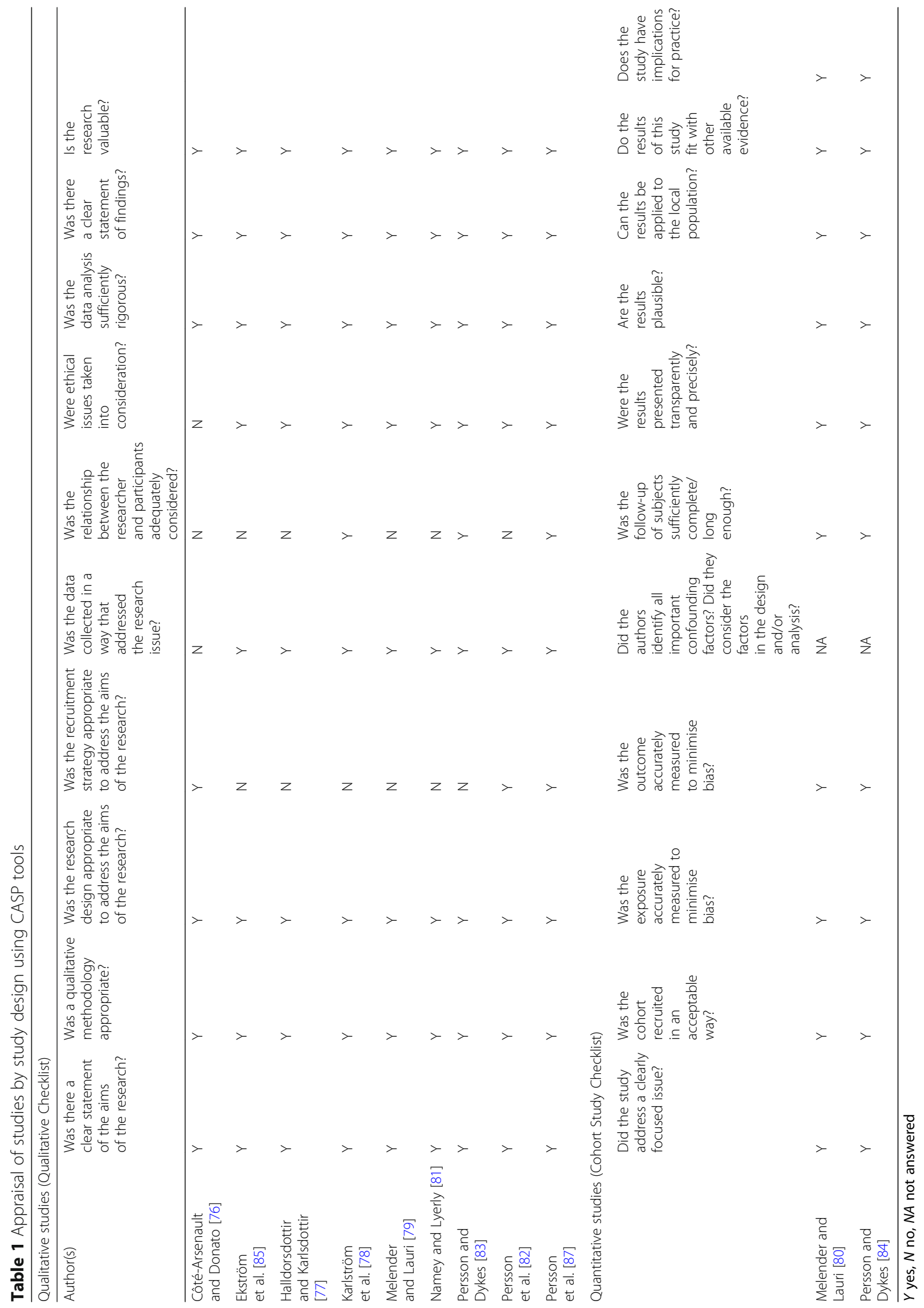




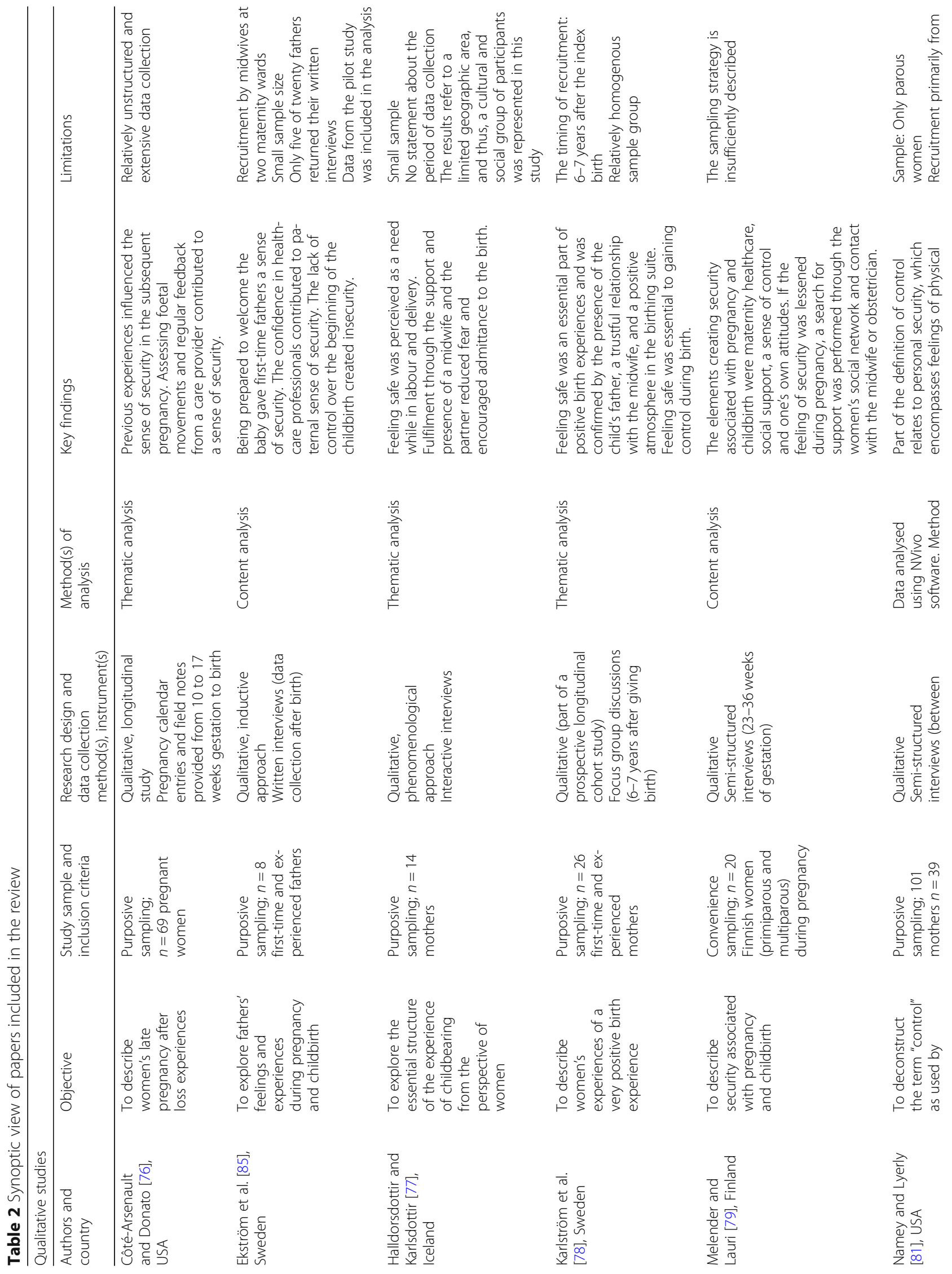




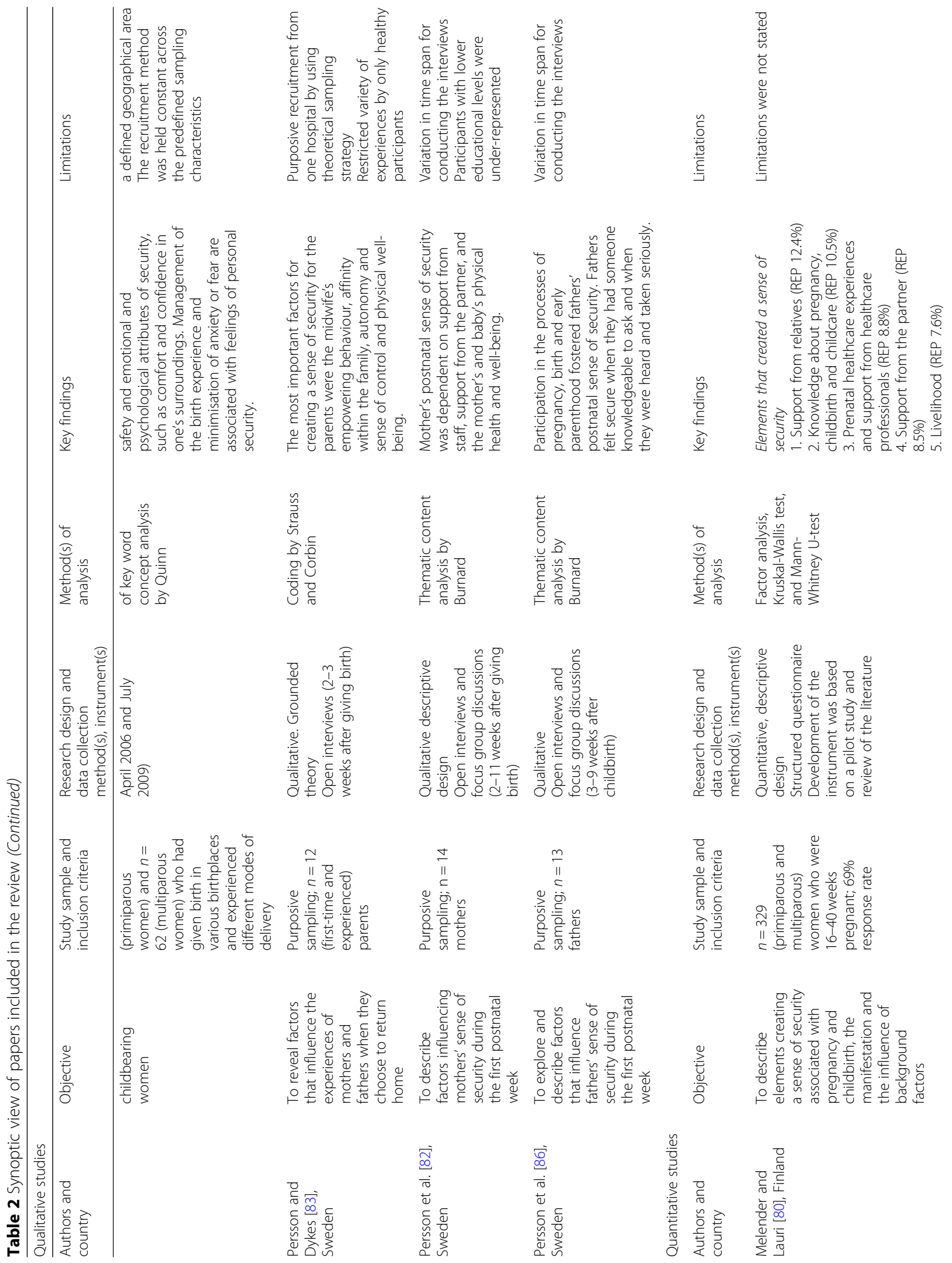




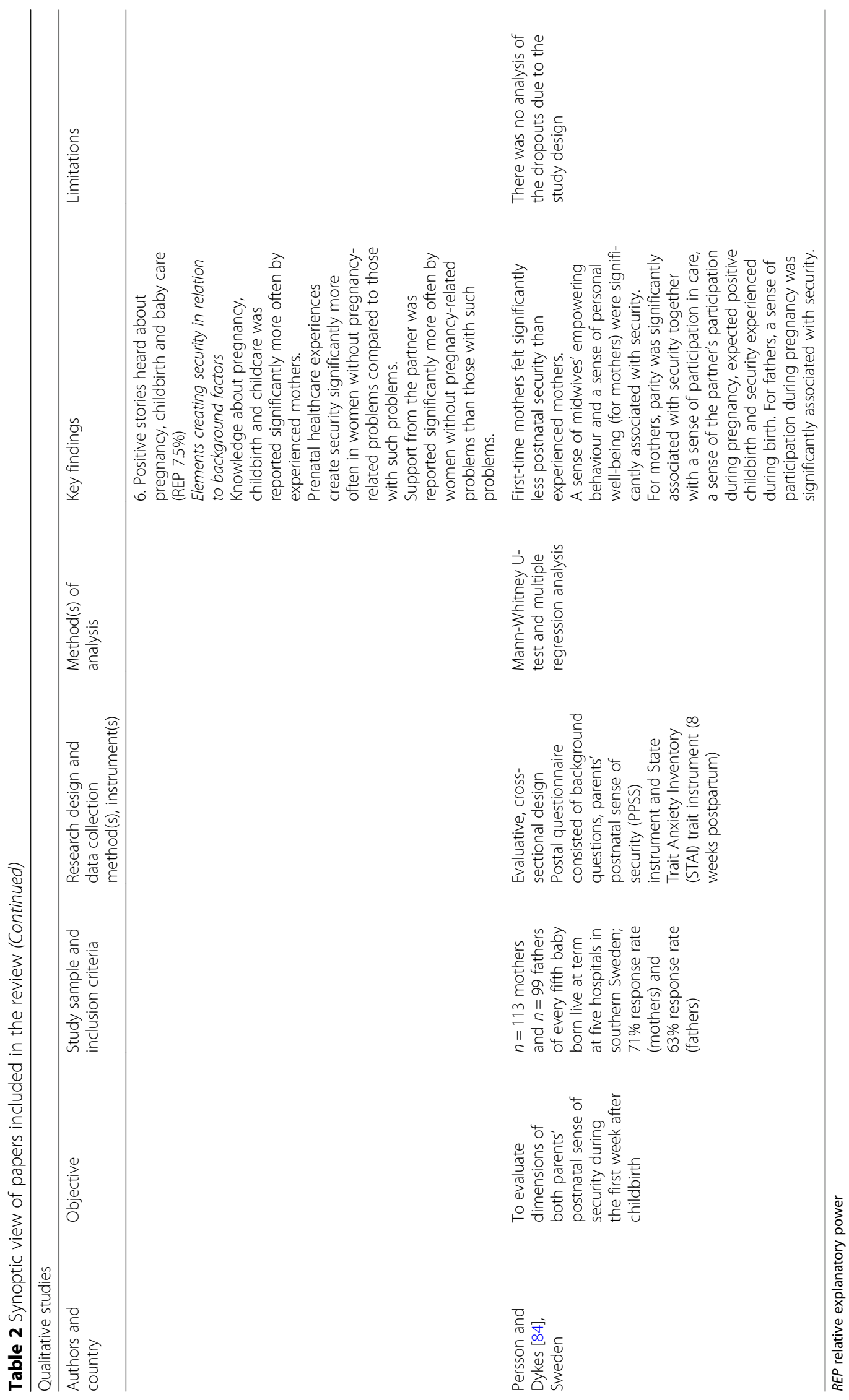


positive feedback and confirmation of normal development during pregnancy can strengthen body confidence and increase mothers' sense of security.

A subtle reference to a relationship between fathers' feelings of security and confidence is reported in only the manuscript published by Ekström et al. [85]. The perceived competence of healthcare professionals contributes to the confidence that fathers have in caregivers and creates a sense of security.

Theme 3. The lack of feeling secure and coping strategies The implied inverse connection of sense of security, confidence, feeling of control and lack of anxiety with sense of insecurity, lack of trust, lack of control and feelings of anxiety has been demonstrated. In their qualitative study, Halldorsdottir and Karlsdottir [77] concluded that when women lose their sense of control due to a perceived lack of caring or lack of security, they can develop feelings of helplessness and perceive their birth as an unbearable experience. Côté-Arsenault and Donato [76] concluded that previous loss experiences have negative impacts on the sense of security in subsequent pregnancies; the sense of security in these situations is often described as fragile and can be rapidly undermined by problems emerging during pregnancy. Regular responses from the baby in the form of foetal movements, more frequent prenatal visits and ultrasounds, and positive feedback from the care provider contribute to a sense of security by providing as much data as possible [76]. Melender and Lauri [79] reported similar results regarding coping strategies. The authors concluded that if the sense of security decreases during pregnancy, women first attempt to cope by searching for social support and talking with their partner before seeking contact with healthcare providers. This coping strategy is based on the intensification of contact with the individual's partner and medical care providers to maintain a confirmation of normality $[76,79]$.

For fathers, the lack of control over the beginning of the birth creates insecurity, and fathers may feel excluded and dependent on information from the mother [85]. In addition, anxiety over not arriving to the delivery ward in time or even having to deliver the baby themselves creates feelings of insecurity, which result in doubts about one's own abilities [85]. The included studies did not investigate fathers' strategies for coping with subjective perceived insecurity.

\section{Theme 4. Factors influencing sense of security}

Melender and Lauri $[79,80]$ made major contributions to the description of sense of security associated with pregnancy and childbirth. In their qualitative study [79], women described the following elements associated with feelings of security: pregnancy care and related positive experiences, social support (particularly by the partner), and information on pregnancy, childbirth, child care and women's lifestyle. In a subsequent quantitative study, Melender and Lauri [80] assessed the elements that create security and the influence of socio-biographical factors on the feeling of security. Security-promoting elements (social support from the family, knowledge about pregnancy, positive nursing experience, partner support, financial situation and positive experience with multiple children) are positively assessed by women as a whole. Sociobiographical factors also affect the security experience, as women with no pregnancy problems feel significantly more secure than women with pregnancy problems, and similar observations have been made between experienced mothers and first-time mothers [80]. Regarding parity, Persson and Dykes [84] reached a similar conclusion that first-time mothers feel significantly less secure than experienced mothers.

Persson and Dykes [83, 84] investigated a common perspective of parents related to the sense of security during the postnatal period. A qualitative study [83] demonstrated that positive, empowerment-motivating behaviours promoted by midwives, affinity towards family, physical well-being and autonomy are the most important factors for creating a sense of security during the first postnatal week.

For fathers, continuous participation during pregnancy is significantly associated with feelings of security [84]. The results of a further qualitative study performed by Persson et al. [86] regarding fathers' security experiences support the previous findings and indicate that fathers' postnatal sense of security emerges from participation in and experiences of the pregnancy, childbirth and early parenthood processes. The authors conclude that aspects of antenatal care are influencing factors that contribute to the feeling of security. Fathers' participation in the pregnancy and childbearing processes is based on self-motivation and achieved via participation in parental education meetings or antenatal visits and dialogue with friends $[83,85,86]$. However, participation is essentially dependent on the support of the healthcare professionals and women themselves. Fathers feel secure if they have a sense of participation during pregnancy and decision making during birth $[83,84,86]$, have a feeling of being taken care of during childbirth $[85,86]$ and are heard and taken seriously [86]. Persson et al. [82] concluded that fathers do not regard the postnatal weeks as an isolated time but rather as a phase in the parenthood process that indicates a dependency of the feeling of security on the time of pregnancy and birth and participation in the processes.

Most of the included studies contributed to answering the second research question and presented a broad spectrum of internal and external factors influencing 
parents' sense of security. The internal factors of mothers (Table 3) can be summarised in the following groups: emotional states, knowledge/experiences, and

Table 3 Factors influencing mothers' sense of security

\begin{tabular}{|c|c|}
\hline \multirow[t]{16}{*}{ Internal factors } & Emotional state, knowledge and experiences \\
\hline & — Sense of control [78-81] \\
\hline & - Autonomy [81] \\
\hline & — Comfort [81] \\
\hline & — Feeling of not being alone [79] \\
\hline & $\begin{array}{l}\text { - Confidence in ability to give birth } \\
{[78,81,83]}\end{array}$ \\
\hline & — Confidence in one's surroundings [81] \\
\hline & $\begin{array}{l}\text { - Positive attitudes to pregnancy and } \\
\text { childbirth }[79,80]\end{array}$ \\
\hline & $\begin{array}{l}\text { - Knowledge about pregnancy, childbirth } \\
\text { and baby care }[79,80]\end{array}$ \\
\hline & $\begin{array}{l}\text { - Positive stories about pregnancy, childbirth } \\
\text { and baby care }[79,80]\end{array}$ \\
\hline & - Previous childbirth experiences $[79,80,82,84]$ \\
\hline & Physical health of mother and child \\
\hline & — Foetal movements and growth $[76,79,80]$ \\
\hline & — Physical well-being of mother and child [79-84] \\
\hline & — Pregnancy-related complications $[79,80]$ \\
\hline & - Active self-care and care of unborn child [76] \\
\hline \multirow[t]{18}{*}{ External factors } & Attributes and acts of supporting persons \\
\hline & — Presence of a caring midwife [77-79] \\
\hline & $\begin{array}{l}\text { - Support of a caring midwife when } \\
\text { needed }[77,78]\end{array}$ \\
\hline & $\begin{array}{l}\text { - Trustful relationship with a caring } \\
\text { midwife [77-79] }\end{array}$ \\
\hline & $\begin{array}{l}\text { - Support/regular feedback from } \\
\text { healthcare professionals }[76,79,80]\end{array}$ \\
\hline & — Being seen as an individual [82] \\
\hline & — Consistent advice/information $[77,78,82]$ \\
\hline & $\begin{array}{l}\text { - Partner's and own participation in } \\
\text { care }[82,84]\end{array}$ \\
\hline & $\begin{array}{l}\text { - Presence and support of the } \\
\text { partner }[77-80,82,83]\end{array}$ \\
\hline & — Support from relatives [80] \\
\hline & Settings and options of maternity care \\
\hline & — Prenatal visits and ultrasound [76] \\
\hline & $\begin{array}{l}\text { - Medical expertise/maternity } \\
\text { healthcare }[76,79]\end{array}$ \\
\hline & $\begin{array}{l}\text { - Positive atmosphere in the birthing } \\
\text { suite [78] }\end{array}$ \\
\hline & — Avoiding interventions [81] \\
\hline & — Planned follow-up after birth [82] \\
\hline & Personal life situation \\
\hline & — Livelihood $[79,80]$ \\
\hline
\end{tabular}

health states of the mother and child. The external factors consist of attributes and acts of supporting persons, settings and options of maternity care and personal life situations. For fathers, the health states of the mother and child are considered external factors. Summaries of the factors influencing mothers' and fathers' sense of security are presented in Tables 3 and 4, respectively.

\section{Discussion}

The aim of this literature analysis was to examine the phenomenon of sense of security from mothers' and fathers' perspectives in the context of pregnancy, childbirth and the postnatal period. The results demonstrate a broad range of factors influencing the feeling of parental security. For women, the attribution of security as a basic need and central issue in pregnancy, childbirth and the postnatal period represents an important result of the literature analysis and corresponds to sociopsychological findings [19, 24-27]. The pursuit of security during pregnancy, childbirth and the postnatal period is an essential feature that can be regarded as a process characterised by continuous negotiations.

The findings of the analysis suggest a correlation between sense of security and feelings of control and confidence. Being in control during childbirth is an important factor for a woman's birth experience and her well-being [87-90]. Because "control" has been differentially conceptualised in previous research [91], exactly how the control concept is connected with sense of security is not completely understood. Confidence in the ability to give birth is congruent with a woman's self-efficacy for coping with the birth situation [92]. However, it remains unclear whether the sense of security is a cause or a consequence of the sense of control and confidence.

The association between feeling secure and being free from anxiety is theoretically reflected in various references $[15,19,21]$. Analogically, the results implied an association of sense of security with a lack of trust and feelings of anxiety. Experiencing anxiety can negatively impact women's confidence in their birthing ability [93], which can continue during subsequent births [94, 95].

These findings illustrate the significance and importance of the presence of partners and professionals to women's sense of security during birth [78-81]. A trusting relationship between health professionals and the woman giving birth seems to be essential for a mother's sense of security and can strengthen her self-esteem [96]. It can be concluded that a woman's feeling of security is not based exclusively on external competencies and caregivers but is essentially shaped by the nature of her relationship with health professionals. Therefore, midwives and obstetricians can significantly affect the woman's sense of security via the nature of their relationship with the woman. 
Table 4 Factors influencing fathers' sense of security

\begin{tabular}{|c|c|}
\hline \multirow[t]{11}{*}{ Internal factors } & Own emotional state, knowledge and experiences \\
\hline & — Being prepared to welcome the baby $[83,85]$ \\
\hline & — Lack of control over the beginning of birth [85] \\
\hline & $\begin{array}{l}\text { - Concern about not arriving at the delivery } \\
\text { ward in time and having to deliver the baby } \\
\text { themselves [85] }\end{array}$ \\
\hline & — Confidence in healthcare professionals [85] \\
\hline & - Sense of participation during pregnancy $[84,86]$ \\
\hline & $\begin{array}{l}\text { - Sense of participation in decision making } \\
\text { during birth }[83,84,86]\end{array}$ \\
\hline & $\begin{array}{l}\text { - Sense of being responsible for the care of the } \\
\text { mother and the child at home }[83,86]\end{array}$ \\
\hline & — Knowing who to ask [86] \\
\hline & - Previous experiences of childbirth $[85,86]$ \\
\hline & — Affinity to mother of the common child [81] \\
\hline \multirow[t]{24}{*}{ External factors } & States of health of mother and child \\
\hline & — Emotional well-being of the mother [84] \\
\hline & $\begin{array}{l}\text { - Physical well-being of the baby/ability to breast } \\
\text { feed }[83,84,86]\end{array}$ \\
\hline & — Birth without complications $[85,86]$ \\
\hline & - Woman's experiences and knowledge $[85,86]$ \\
\hline & Attributes and acts of supporting persons \\
\hline & $\begin{array}{l}\text { - Competence of healthcare professionals/ } \\
\text { midwives }[85,86]\end{array}$ \\
\hline & - Midwives'/nurses' empowering behaviour $[83,84]$ \\
\hline & — Cooperation with the midwife [85] \\
\hline & - Participation in the care of the baby $[83,86]$ \\
\hline & — Information from friends and midwives [85] \\
\hline & $\begin{array}{l}\text { - Being taken care of and attention during } \\
\text { childbirth }[85,86]\end{array}$ \\
\hline & — Being heard and taken seriously [86] \\
\hline & $\begin{array}{l}\text { - Being given confirmation about the } \\
\text { normality of the situation [86] }\end{array}$ \\
\hline & $\begin{array}{l}\text { - Being given relevant and consistent } \\
\text { information and explanations [86] }\end{array}$ \\
\hline & Settings and options of maternity care \\
\hline & - Participation in antenatal visits $[83,86]$ \\
\hline & — Parental education meetings [85] \\
\hline & $\begin{array}{l}\text { - The opportunity to be together with } \\
\text { the mother and child at hospital [86] }\end{array}$ \\
\hline & — Postnatal visits at home [83] \\
\hline & $\begin{array}{l}\text { - Available medical resources after } \\
\text { childbirth }[83,85]\end{array}$ \\
\hline & Personal live situation \\
\hline & — Returning home after childbirth [86] \\
\hline & $\begin{array}{l}\text { - Possibility of being together with the } \\
\text { mother and child at home [86] }\end{array}$ \\
\hline
\end{tabular}

Regardless of the role of health professionals, the importance of the partner's presence and support to the woman's feeling of security is undeniable [78-81, 83, 84]. The importance of the father's presence to the woman's sense of security has already been mentioned in several studies concerning fathers' childbirth experiences [49-51]. Having familiar person by their side appears to be important for helping women mentally deal with the uncertainty of the birth process. This role cannot be equated to the presence and support of health professionals given their various tasks and responsibilities. The woman's need for her partner's participation in the processes of pregnancy, childbirth and the postnatal period indicate that women understand the transitional phases as familial processes shared with their male partners.

For fathers, participation seems to be essential for their sense of security [84-86]. Further studies regarding fathers' childbirth experiences have shown that having knowledge about childbirth and receiving information during the childbirth process increase the fathers' sense of security and is accompanied by a sense of control [46, 9799]. Fathers feel less involved and thus insecure if they do not receive needed information [98, 100]. On the other hand, fathers often try to hide their feelings of insecurity behind a confident and calm façade to support their female partner [101]. While women's sense of control and confidence in themselves and their ability to give birth can create feelings of security, fathers' sense of security reveals an exclusive dependence on their female partners and professionals. However, the presence and support of the caring professionals appears to be a factor connecting mothers and fathers. Support plays an essential role in developing confidence in caregivers and thus in creating a sense of security for both partners. Nevertheless, conclusions regarding the father's security experiences are limited by the small number of included studies; only one study focused on the birth experience, and the remaining studies were restricted to the first postpartum week.

These findings indicate that a sense of security is characterised by an emotional, social and physical-medical dimension that has previously been described in some of the included studies [81, 83]. According to this viewpoint, the emotional dimension of feeling secure is represented by confidence and a sense of control and associated with freedom from anxiety [79-82, 86]. The social dimension of sense of security is reflected in the support and presence of the partner and in connections with other family members $[78-81,83,84]$. The physical-medical dimension is revealed on the one hand by the physical well-being of the woman and child [76, $79-84,86]$ and on the other hand by the maternity care $[76,79,82,83,86]$ and professional skills of the caregivers [77-80, 85, 86]. In turn, the perceived competence of the healthcare professionals plays an essential role in 
building a trusting relationship with the caregivers and can thus also be assigned to the emotional dimension of sense of security. The physical well-being of the mother and child seems to be another factor connecting the parents' sense of security. Analogies to the perception and interpretation of the safety concept can be identified, and thus, from the women's viewpoint, both concepts are not clearly separated from each other in the context of maternity care.

This integrative review synthesises a number of studies using diverse methodologies that were conducted in different health care systems. Methodological weaknesses regarding the recruitment or sample strategy were found in almost all of the qualitative studies. However, the included studies present a broad spectrum of internal and external factors influencing mothers' and fathers' sense of security and provide the opportunity for further specific recommendations. The results do not demonstrate an existing concept of sense of security or a consistent definition, and the findings of the influencing factors are mainly descriptive and less explanatory. Less is known about the causality between the security-creating determinants, which indicates that further qualitative studies exploring the constitution of sense of security in the context of childbirth are recommended. Furthermore, the present literature focuses primarily on the perspectives of pregnant women and mothers, whereas the fathers' perspectives have been underresearched and are limited to the postpartum phase. Future studies are needed to exclusively investigate fathers' perceptions of security experiences and needs during pregnancy or childbirth. The majority of participating women in several of the included studies were recruited from only the hospital setting. Further research considering different birth places and different modes of birth could better explain the influences of these factors on sense of security. Additionally, a common perspective of parents in the context of childbirth has not been investigated. Little is known about how parents experience and construct their own security in the context of childbirth. Further research is needed to fill this gap with respect to experiences of sense of security from the viewpoints of both parents.

These results summarise the perceptions of parents, in most cases of mothers from geographically and culturally diverse countries with different maternity care systems. Social and cultural backgrounds may influence mothers' and fathers' perceptions of security [31, 32]. Furthermore, there is a language-specific interpretative framework of the concept of security, as the term security is not distinguished from the concept of safety in German (Sicherheit) or Swedish (Trygghet). For this reason, obtaining feedback and knowledge of the experiences of parents within country-specific care systems is important and indicates the need for research in the local care context.

\section{Limitations}

This review is potentially limited by the key phrases used in the database search. Therefore, not all of the relevant studies may have been found, as the search was limited to two biomedical and health science databases, one psychological science database and one German language social science database. In addition, the translation and interpretation of security and safety remain difficult and thus may lead to incomplete results. A further limitation is the integration of selected, security-relevant results from studies addressing different research questions. Finally, the selection of included articles was performed by only one researcher. To avoid possible bias, article selection should have been performed independently by two researchers. To minimise the methodological bias, the co-authors were continuously involved in the research process, and the thematic analysis results were discussed. Despite these limitations, this integrative literature review provides a broad overview of the knowledge related to parents' sense of security during pregnancy, childbirth and the postnatal period and describes the factors that influence their feeling of security.

\section{Conclusions}

This integrative review examined current knowledge of parents' security experiences in the context of pregnancy, childbirth and the postnatal period. Previous findings from data analysis have indicated that the perception of security is highly complex and depends on multiple internal and external factors that can also differ between mothers and fathers. For mothers, the attribution of security as a basic need and central issue in pregnancy, childbirth and the postnatal period is a key result of the literature analysis. These results suggest a correlation between sense of security and feelings of control and confidence, showing the significance of partners' and professionals' support for a woman's sense of security during birth. For fathers, participation seems to be essential for their sense of security. Research on the subjective experiences and perceptions of fathers pertaining to security is lacking. Little is known about the causality between security-related factors and sense of security. Further studies are needed to explore the constitution of sense of security in the context of childbirth. Additionally, further research focused on the experiences of security from the perspectives of fathers or both partners is necessary.

For both parents, the presence and support of midwives and other professional caregivers play important roles in developing confidence in the caregivers. A trusting relationship with midwives and other healthcare professionals is associated with parents' sense of security. As such, midwives and other involved health professionals should be aware of their role in creating a sense of 
security among parents. Via targeted communication and advice, caregivers must determine what women and their partners need to feel secure during pregnancy, childbirth and the postnatal period. Based on these findings and a culture-specific understanding of security, midwives and other professional caregivers can effectively support parents with regard to their specific security needs and increase their chances for positive experiences during the transition to parenthood.

\section{Acknowledgements}

Not applicable.

\section{Funding}

This research project was funded by the German Federal Ministry of Education and Research (BMBF, project funding reference numbers FKZ: 01KX1113A and FKZ: 01KX1113B) and was conducted at Witten/Herdecke University, Witten, Germany, and Osnabrück University of Applied Sciences, Osnabrück, Germany.

The funding source was not involved in the research design, collection, analysis and interpretation of data, writing of the report and decision to submit the article for publication.

\section{Availability of data and materials}

Not applicable.

\section{Authors' contributions}

TWB, SM and $\mathrm{CH}$ conceptualised the review and selected the review methodology. TWB and KN evaluated the search strategy. TWB conducted the literature search, identified articles for inclusion and analysis, and drafted the initial manuscript. The included articles were discussed with $\mathrm{KN}$ and $\mathrm{CH}$. TWB critically appraised the included studies with partial help from KN. KN, $\mathrm{CP}, \mathrm{SM}$ and $\mathrm{CH}$ contributed to critical revisions of the manuscript. All named authors approved the final manuscript.

\section{Ethics approval and consent to participate}

Not applicable.

\section{Consent for publication}

Not applicable.

\section{Competing interests}

The authors have no competing interests to declare.

\section{Publisher's Note}

Springer Nature remains neutral with regard to jurisdictional claims in published maps and institutional affiliations.

\section{Author details}

${ }^{1}$ Faculty of Health, Department of Nursing Science, Witten/Herdecke University, Stockumer Strasse 12, 58453 Witten, Germany. ${ }^{2}$ Research Group 'FamiLe - Family Health in Life Course', Witten and Osnabrück, Germany. ${ }^{3}$ Faculty of Business Management and Social Sciences, Osnabrück, Osnabrück University of Applied Sciences, Germany, P.O. Box: 1940, 49009 Osnabrück, Germany.

Received: 27 April 2018 Accepted: 19 November 2018

Published online: 04 December 2018

\section{References}

1. Zapf W. Individualisierung und Sicherheit. In: Untersuchungen zur Lebensqualität in der Bundesrepublik Deutschland. Beck Verlag: München; 1987.

2. Auriga R. Sicherheiten - Risiken - Wahrscheinlichkeiten. In: Vom Entstehen eines Sicherheitsgefühls. Berlin: Wissenschaftlicher Verlag. p. 2014

3. Levy-Shiff R. Individual and contextual correlates of marital change across the transition to parenthood. Dev Psychol. 1994;30:591-601. https://doi.org/ 10.1037/0012-1649.30.4.591..
4. Cowan CP, Cowan PA. When partners become parents: the big life change for couples. New York: Harper Collins. 1992.

5. Cowan PA. Individual and family life transitions: a proposal for a new definition. In: Cowan PA, Hetherington EM, editors. Family transitions. Hillsdale, NJ: Lawrence Erlbaum; 1991. p. 3-30.

6. Mozygemba K. Die Schwangerschaft als Statuspassage. Das Einverleiben einer sozialen Rolle im Kontext einer nutzerinnenorientierten Versorgung. Bern: Huber; 2011.

7. Bronte-Tinkew J, Ryan S, Carrano J, Moore KA. Resident fathers' pregnancy intentions, prenatal behaviors, and links to involvement with infants. J Marriage Fam. 2007;69:977-90. https://doi.org/10.1111/j.1741-3737.2007.00425.x.

8. Kuljanić K, Dorčić TM, Bistrović IL, Brnčić-Fischer A. Prospective fathers: psychosocial adaptation and involvement in the last trimester of pregnancy. Psychiatr Danub. 2016;28:386-94.

9. Åsenhed L, Kilstam J, Alehagen S, Baggens C. Becoming a father is an emotional roller coaster-an analysis of first-time fathers' blogs. J Clin Nurs. 2014:23:1309-17. https://doi.org/10.1111/jocn.12355.

10. Chalmers B, Meyer D. What men say about pregnancy, birth and parenthood. J Psychosom Obstet Gynaecol. 1996;17:47-52. https://doi.org/ 10.3109/01674829609025663.

11. Finnbogadóttir H, Crang Svalenius EC, Persson EK. Expectant first-time fathers' experiences of pregnancy. Midwifery. 2003;19:96-105. https://doi. org/10.1016/S0266-6138(03)00003-2.

12. Hanson S, Hunter LP, Bormann JR, Sobo EJ. Paternal fears of childbirth: a literature review. J Perinat Educ. 2009;18:12-20. https://doi.org/10.1624/ $105812409 \times 474672$

13. Baldwin DA. The concept of security. Rev Int Stud. 1997;23:5-26. https://doi. org/10.1017/S0260210597000053.

14. Buzan B, Wæver O, Wilde J. Security: a new framework for analysis. Boulder: Lynne Rienner. 1998.

15. Zedner $L$. The concept of security: an agenda for comparative analysis. Legal stud. 2003;23:153-76. https:/doi.org/10.1111/j.1748-121X.2003.tb00209.x.

16. Ale B. Risk: an introduction. Oxon: Routledge; 2009.

17. Buzan B. People, states and fear. Boulder: Lynne Rienner; 1991.

18. Glaeßner GJ. Sicherheit in Freiheit. In: Die Schutzfunktion des demokratischen Staates und die Freiheit der Bürger. Opladen: Leske und Budrich; 2003.

19. Kaufmann FX. Sicherheit als soziologisches und sozialpolitisches Problem. In: Untersuchungen zu einer Wertidee hochdifferenzierter Gesellschaften. Berlin: LIT. p. 1973.

20. Ruhne R. Sicherheit ist nicht die Abwesenheit von Unsicherheit - die soziale Konstruktion geschlechtsspezifischer (Un)Sicherheiten im öffentlichen Raum. In: Gestring N, Glasauer H, Hannemann C, Petrowsky W, Pohlan J, editors. Schwerpunkt: die sichere Stadt. Opladen: Leske Budrich; 2003. p. 55-73.

21. Wolfers A. National security as an ambiguous symbol. In: Hughes C, Meng L, editors. Security studies: a reader. Abingdon: Routledge; 2011. p. 5-10.

22. Beck PU. Risk society. Towards a new modernity. London: Sage; 1992.

23. Seifert A. Gefährlichkeitseinschätzung von Autofahrern, Motorradfahrern und Radfahrern. München: LIT; 2007.

24. Bar-Tal D, Jacobson D. A psychological perspective on security. Appl Psychol. 1998;47:59-71. https://doi.org/10.1111/j.1464-0597.1998.tb00013.x.

25. Maslow AH. Motivation and personality. New York: Harper and Row; 1987.

26. Giebel D. Integrierte Sicherheitskommunikation: zur Herausbildung von Unsicherheitsbewältigungskompetenzen durch und in Sicherheitskommunikation. Berlin: LIT; 2012.

27. Kaufmann FX. Normen und Institutionen als Mittel zur Bewältigung von Unsicherheit: Die Sicht der Soziologie. In: Holzheu F, editor. Gesellschaft und Unsicherheit. Karlsruhe: Verlag Versicherungswirtschaft; 1987. p. 37-48.

28. Ziegleder D, Kudlacek D, Fischer T. Zur Wahrnehmung und Definition von Sicherheit durch die Bevölkerung. Erkenntnisse und Konsequenzen aus der kriminologisch-sozialwissenschaftlichen Forschung. Schriftenreihe Sicherheit Nr. 5. Berlin: Freie Universität Verlag; 2011. http://www.sicherheitforschung. de/forschungsforum/schriftenreihe_neu/sr_v_v/SchriftenreiheSicherheit_05. pdf. Accessed 23 Apr 2017

29. "Secure." OED online. London, UK: Oxford University Press; 2017. https://en. oxforddictionaries.com/definition/secure Accessed 26 Oct 2017.

30. Schewe C. Subjektives Sicherheitsgefühl. In: Lange HJ, editor. Wörterbuch zur Inneren Sicherheit. Wiesbaden: VS Verlag für Sozialwissenschaften; 2006. p. 322-5.

31. Havenkamp R. Grundzüge eines Sicherheitsbarometers in Deutschland inhaltliche und methodische Überlegungen. In: Albrecht HJ, Hoch P, Zoche P, editors. Sicherheiten und Unsicherheiten. Berlin: LIT Verlag; 2014. p. 15130. 
32. Porzsolt F. Sicherheit und gefühlte Sicherheit. In: Porzsolt F, editor Grundlagen der klinischen Ökonomik. Berlin: PVS; 2011. p. 170-3.

33. Gusy C. Sicherheitskultur - Sicherheitspolitik - Sicherheitsrecht. Kritische Vierteljahresschrift für Gesetzgebung und Rechtswissenschaft (KritV). 2010; 93:111-28.

34. Dencker A, Taft C, Bergqvist L, Lilja H, Berg M. Childbirth experience questionnaire (CEQ): development and evaluation of a multidimensional instrument. BMC Pregnancy Childbirth. 2010;10(81). https://doi.org/10.1186/ 1471-2393-10-81.

35. Gärtner FR, Freeman LM, Rijnders ME, Middeldorp JM, Bloemenkamp KW, Stiggelbout AM, et al. A comprehensive representation of the birthexperience: identification and prioritization of birth-specific domains based on a mixed-method design. BMC Pregnancy Childbirth. 2014;14:147. https:// doi.org/10.1186/1471-2393-14-147.

36. Odent M. Birth and breastfeeding: rediscovering the needs of women during pregnancy and childbirth. In: West Hoathly: Clairview; 1992.

37. Odent M. Foreword. In: Dick-Read G, editor. Childbirth without fear. London: Pollinger in print; 2006. p. VII-XI.

38. Stenglin $M$, Foureur $M$. Designing out the fear cascade to increase the likelihood of normal birth. Midwifery. 2013;29:819-25. https://doi.org/10. 1016/j.midw.2013.04.005.

39. Palmér L, Carlsson G, Brunt D, Nyström M. Existential security is a necessary condition for continued breastfeeding despite severe initial difficulties: a lifeworld hermeneutical study. Int Breastfeed J. 2015;10:17. https://doi.org/ 10.1186/s13006-015-0042-9

40. Carlsson IM. Being in a safe and thus secure place, the core of early labour: a secondary analysis in a Swedish context. Int J Qual Stud Health WellBeing. 2016;11:30230. https://doi.org/10.3402/qhw.v11.30230.

41. Tarkka MT, Paunonen M. Social support and its impact on mothers' experiences of childbirth. J Adv Nurs. 1996;23:70-5. https://doi.org/10.1111/j. 1365-2648.1996.tb03137.x.

42. Berg M, Lundgren I, Hermansson $\mathrm{E}$, Wahlberg V. Women's experience of the encounter with the midwife during childbirth. Midwifery. 1996;12:11-5. https://doi.org/10.1016/S0266-6138(96)90033-9.

43. Thorstensson S, Ekström A, Lundgren I, Hertfelt Wahn EH. Exploring professional support offered by midwives during labour: an observation and interview study. Nurs Res Practice. 2012;2012:648405. https://doi.org/10. 1155/2012/648405

44. Sjöblom I, Idvall E, Lindgren $\mathrm{H}$. Nordic homebirth research group. Creating a safe haven-women's experiences of the midwife's professional skills during planned home birth in four Nordic countries. Birth. 2014;41:100-7. https://doi.org/10.1111/birt.12092.

45. Bäckström C, Hertfelt Wahn EH. Support during labour: first-time fathers' descriptions of requested and received support during the birth of their child. Midwifery. 2011;27:67-73. https://doi.org/10.1016/j.midw.2009.07.001.

46. Bäckström C, Thorstensson S, Mårtensson LB, Grimming R, Nyblin Y, Golsäter M. To be able to support her, I must feel calm and safe': pregnant women's partners perceptions of professional support during pregnancy. BMC Pregnancy Childbirth. 2017;17:234. https://doi.org/10.1186/s12884-017-1411-8.

47. Lindgren $\mathrm{H}$, Erlandsson $\mathrm{K}$. She leads, he follows-fathers' experiences of a planned home birth. A Swedish interview study. Sex Reprod Healthc. 2011; 2:65-70. https://doi.org/10.1016/j.srhc.2010.12.002.

48. Jouhki MR, Suominen T, Åstedt-Kurki P. Supporting and sharing-home birth: fathers' perspective. Am J Mens Health. 2015;9:421-9. https://doi.org/ $10.1177 / 1557988314549413$.

49. He HG, Vehviläinen-Julkunen K, Qian XF, Sapountzi-Krepia D, Gong Y, Wang W. Fathers' feelings related to their partners' childbirth and views on their presence during labour and childbirth: a descriptive quantitative study. Int J Nurs Practice. 2015;21:71-9. https://doi.org/10.1111/ijn.12339.

50. Kainz G, Eliasson M, von Post I. The child's father, an important person for the mother's well-being during the childbirth: a hermeneutic study. Health Care Women Int. 2010;31:621-35. https://doi.org/10.1080/ 07399331003725499.

51. Vehviläinen-Julkunen K, Liukkonen A. Fathers' experiences of childbirth. Midwifery. 1998;14:10-7. https://doi.org/10.1016/S0266-6138(98)90109-7.

52. Ledenfors $A$, Berterö C. First-time fathers' experiences of normal childbirth. Midwifery. 2016;40:26-31. https://doi.org/10.1016/j.midw.2016.05.013.

53. Runciman W, Hibbert $P$, Thomson R, Van Der Schaaf T, Sherman H, Lewalle P. Towards an international classification for patient safety: key concepts and terms. Int J Qual Health Care. 2009:21:18-26. https://doi.org/10.1093/ intqhe/mzn057.
54. Lothian JA. Risk, safety, and choice in childbirth. J Perinat Educ. 2012;21: 45-7. https://doi.org/10.1891/1058-1243.21.1.45.

55. DeVries RG. Barriers to midwifery: an international perspective. J Perinat Educ. 1992;1:1-10

56. Kringeland T, Möller A. Risk and security in childbirth. J Psychosom Obstet Gynaecol. 2006;27:185-91. https://doi.org/10.1080/01674820600707594.

57. Hausman BL. Risky business: framing childbirth in hospital settings. J Med Humanit. 2005;26:23-38. https://doi.org/10.1007/s10912-005-1050-3.

58. Schücking BA. Kinderkriegen und Selbstbestimmung. In: Schücking BA, editor. Selbstbestimmung der Frau in der Gynäkologie und Geburtshilfe. Göttingen: V \& R Unipress; 2003. p. 21-35.

59. Sayn-Wittgenstein F. Geburtshilfe neu denken: Bericht zur Situation und Zukunft des Hebammenwesens in Deutschland. Bern: Huber; 2007.

60. Bibeau AM. Interventions during labor and birth in the United States: a qualitative analysis of women's experiences. Sex Reprod Healthc. 2014;5: 167-73. https://doi.org/10.1016/j.srhc.2014.10.003.

61. Miller AC, Shriver TE. Women's childbirth preferences and practices in the United States. Soc Sci Med. 2012;75:709-16. https://doi.org/10.1016/j. socscimed.2012.03.051.

62. Grigg C, Tracy SK, Daellenbach R, Kensington M, Schmied V. An exploration of influences on women's birthplace decision-making in New Zealand: a mixed methods prospective cohort within the evaluating maternity units study. BMC Pregnancy Childbirth. 2014;14:210. https://doi.org/10.1186/1471-2393-14-210.

63. Regan M, McElroy K. Women's perceptions of childbirth risk and place of birth. J Clin Eth. 2013;24:239-52.

64. MacKenzie Bryers $H$, van Teijlingen E. Risk, theory, social and medical models: a critical analysis of the concept of risk in maternity care. Midwifery. 2010;26:488-96. https://doi.org/10.1016/j.midw.2010.07.003.

65. Howarth A, Swain N, Treharne GJ. The safety-net: what influences New Zealand first-time mothers' perceptions of safety for self and unborn child? New Zealand College of Midwives Journal. 2013;48:24-8.

66. Lothian JA. Being safe: making the decision to have a planned home birth in the United States. J Clin Eth. 2013;24:266-75.

67. Smythe E. Safety is an interpretive act: a hermeneutic analysis of care in childbirth. Int J Nurs Stud. 2010;47:1474-82. https://doi.org/10.1016/j.jijnurstu. 2010.05.003.

68. Magee $H$, Askham $H$. Women's views about safety in maternity care. A qualitative study. Picker institute Europe. King's Fund; 2008. p. 1-45. https:// www.picker.org/wp-content/uploads/2014/10/Womens-views-about-safetyin-maternity-care.pdf. Accessed 3 Feb 2017.

69. Dahlen HG, Barclay LM, Homer C. Preparing for the first birth: mothers' experiences at home and in hospital in Australia. J Perinat Educ. 2008;17: 21-32. https://doi.org/10.1624/105812408X364143.

70. Hadjigeorgiou E, Kouta C, Papastavrou E, Papadopoulos I, Mårtensson LB. Women's perceptions of their right to choose the place of childbirth: an integrative review. Midwifery. 2012;28:380-90. https://doi.org/10.1016/j. midw.2011.05.006.

71. Whittemore R, Knafl K. The integrative review: updated methodology. J Adv Nurs. 2005;52:546-53. https://doi.org/10.1111/j.1365-2648.2005.03621.x.

72. Critical appraisal skills programme (CASP). Making sense of evidence. CASP Qual Res checklist. [Online]. CASP UK, London; 2016. http://media.wix.com/ ugd/dded87_29c5b002d99342f788c6ac670e49f274.pdf Accessed 20 Nov 2017.

73. Critical appraisal skills programme (CASP). Making sense of evidence. CASP cohort study checklist. [Online]. CASP UK, London; 2016. http://docs. wixstatic.com/ugd/dded87 5ad0ece77a3f4fc9bcd3665a7d1fa91f.pdf. Accessed 12 Dec 2017

74. Von Elm E, Altman DG, Egger M, Pocock SJ, Gøtzsche PC, Vandenbroucke $J P$, et al. The strengthening the reporting of observational studies in epidemiology (STROBE) statement: guidelines for reporting observational studies. PLoS Med. 2007;e296:4. doi.org/10.1371/journal.pmed.0040296.

75. Braun V, Clarke V. Using thematic analysis in psychology. Qual Res Psychol. 2006:3:77-101. https://doi.org/10.1191/1478088706qp063oa.

76. Côté-Arsenault D, Donato KL. Restrained expectations in late pregnancy following loss. J Obstet Gynecol Neonatal Nurs. 2007;36:550-7. https://doi. org/10.1111/j.1552-6909.2007.00185.x.

77. Halldorsdottir S, Karlsdottir SI. Journeying through labour and delivery: perceptions of women who have given birth. Midwifery. 1996;12:48-61. https://doi.org/10.1016/S0266-6138(96)90002-9.

78. Karlström A, Nystedt A, Hildingsson I. The meaning of a very positive birth experience: focus groups discussions with women. BMC Pregnancy Childbirth. 2015;15:251. https://doi.org/10.1186/s12884-015-0683-0. 
79. Melender HL, Lauri S. Security associated with pregnancy and childbirth - experiences of pregnant women. J Psychosom Obstet Gynaecol. 2001;22:229-39. https://doi.org/10.3109/01674820109049978.

80. Melender HL, Lauri S. Experiences of security associated with pregnancy and childbirth: a study of pregnant women. Int J Nurs Pract. 2002;8:289-96. https://doi.org/10.1046/j.1440-172X.2002.00382.x.

81. Namey EE, Lyerly AD. The meaning of "control" for childbearing women in the US. Soc Sci Med. 2010;71:769-76. https://doi.org/10.1016/.socscimed. 2010.05.024.

82. Persson EK, Fridlund B, Kvist L, Dykes AK. Mothers' sense of security in the first postnatal week: interview study. J Adv Nurs. 2011;67:105-16. https://doi. org/10.1111/j.1365-2648.2010.05485.x.

83. Persson EK, Dykes AK. Parents' experience of early discharge from hospital after birth in Sweden. Midwifery. 2002;18:53-60. https://doi.org/10.1054/ midw.2002.0291.

84. Persson EK, Dykes AK. Important variables for parents' postnatal sense of security: evaluating a new Swedish instrument (the PPSS instrument). Midwifery. 2009;25:449-60. https://doi.org/10.1016/j.midw.2007.08.001.

85. Ekström A, Arvidsson K, Falkenström M, Thorstensson S. Fathers' feelings and experiences during pregnancy and childbirth: a qualitative study. J Nurs Care. 2013;2:136.

86. Persson EK, Fridlund B, Kvist LJ, Dykes AK. Fathers' sense of security during the first postnatal week - a qualitative interview study in Sweden. Midwifery. 2012;28:e697-704. https://doi.org/10.1016/j.midw.2011.08.010.

87. Cook K, Loomis C. The impact of choice and control on women's childbirth experiences. J Perinat Educ. 2012;21:158-68. https://doi.org/10.1891/10581243.21.3.158

88. Hardin AM, Buckner EB. Characteristics of a positive experience for women who have unmedicated childbirth. J Perinat Educ. 2004;13:10-6. https://doi. org/10.1624/105812404X6180.

89. Hodnett ED. Personal control and the birth environment: comparisons between home and hospital settings. J Environ Psychol. 1989;9:207-16. https://doi.org/10.1016/50272-4944(89)80035-0.

90. Waldenström U. Experience of labor and birth in 1111 women. J Psychosom Res. 1999:47:471-82. https://doi.org/10.1016/S0022-3999(99)00043-4.

91. Green JM, Baston HA. Feeling in control during labor: concepts, correlates. and consequences Birth. 2003;30:235-47. https://doi.org/10.1046/j.1523536X.2003.00253.x.

92. Lowe NK. Self-efficacy for labor and childbirth fears in nulliparous pregnant women. J Psychosom Obstet Gynaecol. 2000;21:219-24. https://doi.org/10. 3109/01674820009085591.

93. Nilsson C, Lundgren I. Women's lived experience of fear of childbirth. Midwifery. 2009;25:e1-9. https://doi.org/10.1016/j.midw.2007.01.017.

94. Zar M, Wijma K, Wijma B. Pre- and postpartum fear of childbirth in nulliparous and parous women. Scand J Behav Ther. 2001;30:75-84. https:// doi.org/10.1080/02845710121310

95. Waldenström U, Hildingsson I, Ryding EL. Antenatal fear of childbirth and its association with subsequent caesarean section and experience of childbirth. BJOG. 2006;113:638-46. https://doi.org/10.1111/j.1471-0528.2006.00950.x.

96. Lundgren I, Berg M. Central concepts in the midwife-woman relationship. Scand J Caring Sci. 2007;21:220-8. https://doi.org/10.1111/j.1471-6712.2007. 00460.x.

97. Longworth $\mathrm{HL}$, Kingdon CK. Fathers in the birth room: what are they expecting and experiencing? a phenomenological study. . Midwifery 2011; 27:588-594 [doi:https://doi.org/10.1016/..midw.2010.06.013.

98. Johansson M, Rubertsson C, Rådestad I, Hildingsson I. Childbirth-an emotionally demanding experience for fathers. Sex Reprod Healthc. 2012;3: 11-20. https://doi.org/10.1016/j.srhc.2011.12.003.

99. Johansson M, Hildingsson I. Intrapartum care could be improved according to Swedish fathers: mode of birth matters for satisfaction. Women Birth. 2013;26:195-201. https://doi.org/10.1016/j.wombi.2013.04.001.

100. Premberg Å, Carlsson G, Hellström AL, Berg M. First-time fathers' experiences of childbirth—a phenomenological study. Midwifery. 2011;27: 848-53. https://doi.org/10.1016/j.midw.2010.09.002.

101. Premberg A, Hellström AL, Berg M. Experiences of the first year as father. Scand J Caring Sci. 2008;22:56-63. https://doi.org/10.1111/j.1471-6712.2007. 00584.x.

\section{Ready to submit your research? Choose BMC and benefit from}

- fast, convenient online submission

- thorough peer review by experienced researchers in your field

- rapid publication on acceptance

- support for research data, including large and complex data types

- gold Open Access which fosters wider collaboration and increased citations

- maximum visibility for your research: over $100 \mathrm{M}$ website views per year

At $\mathrm{BMC}$, research is always in progress.

Learn more biomedcentral.com/submissions 